\title{
RAPD analysis of southern populations of Gammarus locusta: comparison with allozyme data and ecological inferences
}

\author{
Filipe O. Costa ${ }^{1, *}$, Teresa Neuparth ${ }^{1}$, Chris W. Theodorakis ${ }^{2}$, M. Helena Costa ${ }^{1}$, \\ Lee R. Shugart ${ }^{3}$ \\ ${ }^{1}$ IMAR-Centro de Modelação Ecológica, DCEA, FCT, Universidade Nova de Lisboa, 2829-516 Caparica, Portugal \\ ${ }^{2}$ The Institute of Environmental and Human Health, Department of Environmental Toxicology, Texas Tech University, \\ Lubbock, Texas 79409-1163, USA \\ ${ }^{3}$ L.R. Shugart and Associates, PO Box 5564, Oak Ridge, Tennessee 37831, USA
}

\begin{abstract}
The genetic variability of southern European populations of the marine amphipod Gammarus locusta (L.) was analyzed using randomly amplified polymorphic DNA (PCR-RAPD). We analyzed 4 populations along the Portuguese coast with 10 arbitrary primers, which produced a total of 114 interpretable bands. The average percentage of polymorphism was $77 \%$ and the within-population average similarity index was high (0.841). Between-population differentiation was low, as determined by Wright's fixation index, $F_{\mathrm{ST}}(0.074)$, analysis of molecular variance (AMOVA) $\Phi_{\mathrm{ST}}(0.048)$, and Nei's unbiased distances (mean 0.032). These results are consistent with those of previous allozyme analysis, which indicated that G. locusta has low intra- and inter-population genetic variability. Low between-population differentiation indicates that G. locusta has efficient dispersal mechanisms for an organism lacking larval stages and that disperses passively. Despite the low level of genetic differentiation it was still possible to detect some genetic subdivision. The Sado and Alvor populations clustered together consistently in dendograms based on several genetic distances, and AMOVA analysis indicated some level of differentiation between populations located to the north (Aveiro and Foz do Arelho) versus southern populations (Sado and Alvor), albeit this was very low $(<1.5 \%)$. Analysis of migration patterns suggested that dispersal is unbalanced, occurring primarily from west coast populations to the south coast population of Alvor, with much less reciprocal dispersal. It would be worthwhile inspecting the significance of this unbalanced north-south flow, by determining whether populations located east of Alvor also exibit such unbalanced dispersal relative to west coast populations.
\end{abstract}

KEY WORDS: Gammarus locusta $\cdot$ Amphipod $\cdot$ Genetic variability $\cdot$ Random amplified polymorphic DNA $\cdot$ Allozymes $\cdot$ Gene flow $\cdot$ Dispersal $\cdot$ Migration

Resale or republication not permitted without written consent of the publisher

\section{INTRODUCTION}

Amphipods of the genus Gammarus are relevant ecological components of many European coastal ecosystems. Among them, G. locusta (L.) is a particularly interesting species from an ecological and biogeographic perspective. Compared with other Gammarus species of the so-called G. zaddachi group from northern Europe, G. locusta is the species with the widest latitudinal distribution, occurring from Iceland and Norway to the south of Portugal (Costa \& Costa 2000). It is the only representative of northern European Gammarus on the Portuguese coast, where other Gammarus spp. from the Mediterranean Sea occur, namely G. insensibilis, G. aequicauda, G. crinicornis and G. chevreuxi (Maren 1975, Marques 1989). According to current knowledge, G. locusta does not occur in the Mediterranean Sea, although in the past it 
was mistakenly recorded there. The southern limit of G. locusta's distribution is therefore Cadiz Bay (southern Spanish Atlantic coast) (Costa \& Costa 2000), located just west of the Gibraltar Strait, the entrance to the Mediterranean Sea. G. locusta is also a relevant organism for ecotoxicological research, and has been proposed and used as a test organism in ecotoxicological studies, particularly of marine and estuarine sediments (Costa et al. 1998, Neuparth et al. 2002). Together, these features make it an attractive model organism for ecological and ecotoxicological research in Atlantic European coastal ecosystems.

Despite the ecological relevance of Gammarus locusta and other marine Gammarus spp., research on the population genetics of these amphipods is sparse. Environmental conditions are recognized to have an impact on population genetic structure (Hilbish 1996, Hogg et al. 1999, Theodorakis \& Shugart 1999). Environmental insult has been shown to be able to reduce the genetic diversity of populations either by selective or stochastic processes (Bickham et al. 2000). This is of concern because it is widely contended that there is a direct relationship between the genetic variability of a population and its ability to adapt to environmental stresses. In this context, the application of parameters of population genetic diversity as monitoring tools of wildlife vulnerability to environmental stress has been increasingly encouraged (Krane et al. 1999, Bickham et al. 2000, Silbiger et al. 2001, Theodorakis et al. 2001).

The genetic analysis of natural populations of Gammarus locusta can be of great assistance in ecological and ecotoxicological studies with southern populations of this amphipod (e.g. Costa et al. 1998, Costa \& Costa 1999, 2000, Neuparth et al. 2002). Genetic studies may provide insight into dispersal mechanisms and gene flow patterns among G. locusta populations, which could contribute to a better understanding of its population dynamics, seasonal growth and senescence cycles, and its geographical and ecological distribution. They may also help to ascertain the role of genotypic diversity in the responses of natural populations to environmental disturbances and threats.

Until recently, genetic studies performed on Gammarus locusta were limited to some northern European populations (Kolding 1985, Siegismund et al. 1985). Coelho et al. (2002) examined for the first time G. locusta populations near the southern distribution limit of the species, in a study entailing analysis of allozyme variation in 5 G. locusta populations on the Portuguese coast. It was observed that these populations exhibit low inter- and intra-population variability, which is consistent with studies of northern European populations, for which very low levels of genetic variability were also recorded. This is also consistent with recent studies reporting low genetic variability in amphipod species with a continuous distribution (Hogg et al. 1999, 2000).

Since the allozyme results cannot distinguish any geographic pattern in the genetic structure of southern populations of Gammarus locusta, molecular markers with improved resolution are required to elucidate the genetic relationships between these populations and verify findings obtained with allozyme analysis (e.g. Heipel et al. 1998, Exadactylos et al. 2003, Star et al. 2003). One such molecular technique is random amplified polymorphic DNA (RAPD) fingerprinting. As opposed to allozyme electrophoresis, RAPD has been rarely applied in genetic studies of amphipods. However, this technique has been increasingly applied to elucidate the genetic structure of natural populations of numerous vertebrate and invertebrate species (Heipel et al. 1998, Mamuris et al. 1999, McCormack et al. 2000, Ulrich et al. 2001, Congiu et al. 2002). It has also been successfully applied to amphipods in at least 2 studies (Thomas et al. 1997, Wilson et al. 1997). The main advantages of this technique are that no previous knowledge of the genome sequences of the target organism is necessary, and a high number of molecular markers can be examined with comparatively little equipment, cost and technical effort. In this study we present results from an analysis, using 10 primers, of 4 populations of G. locusta on the Portuguese coast. Results derived with RAPD analysis are compared with those previously obtained by allozyme electrophoresis and their implications to the known distribution and ecology of G. locusta discussed.

\section{MATERIALS AND METHODS}

Amphipod collection and processing. Gammarus locusta populations were sampled from 4 locations along the Portuguese coast; these were, from north to south, Ria de Aveiro, Foz do Arelho (mouth of the Óbidos lagoon), Sado Estuary and Ria de Alvor (Fig. 1). Live amphipods were brought to the laboratory and identified under a binocular microscope. Morphological identification was based on keys and drawings of Stock (1967) and Lincoln (1979). A total of 79 individuals confirmed as G. locusta were isolated, comprising 19 specimens from Ria de Alvor and 20 from each of the remaining populations.

DNA extraction. DNA was isolated from live individuals immediately after taxonomic verification. Whole amphipods were homogenized in a $1.5 \mathrm{ml}$ microtube containing $500 \mu \mathrm{l}$ TEN (50 mM Tris, 25 mM EDTA and $100 \mathrm{mM} \mathrm{NaCl}$ ). Following addition and mixing with $50 \mu \mathrm{l}$ of $10 \%$ sarcosyl, the resultant solution was extracted with PCI (phenol:chloroform:isoamyl alcohol, 25:24:1, v/v/v) and subsequently with chloroform. The 


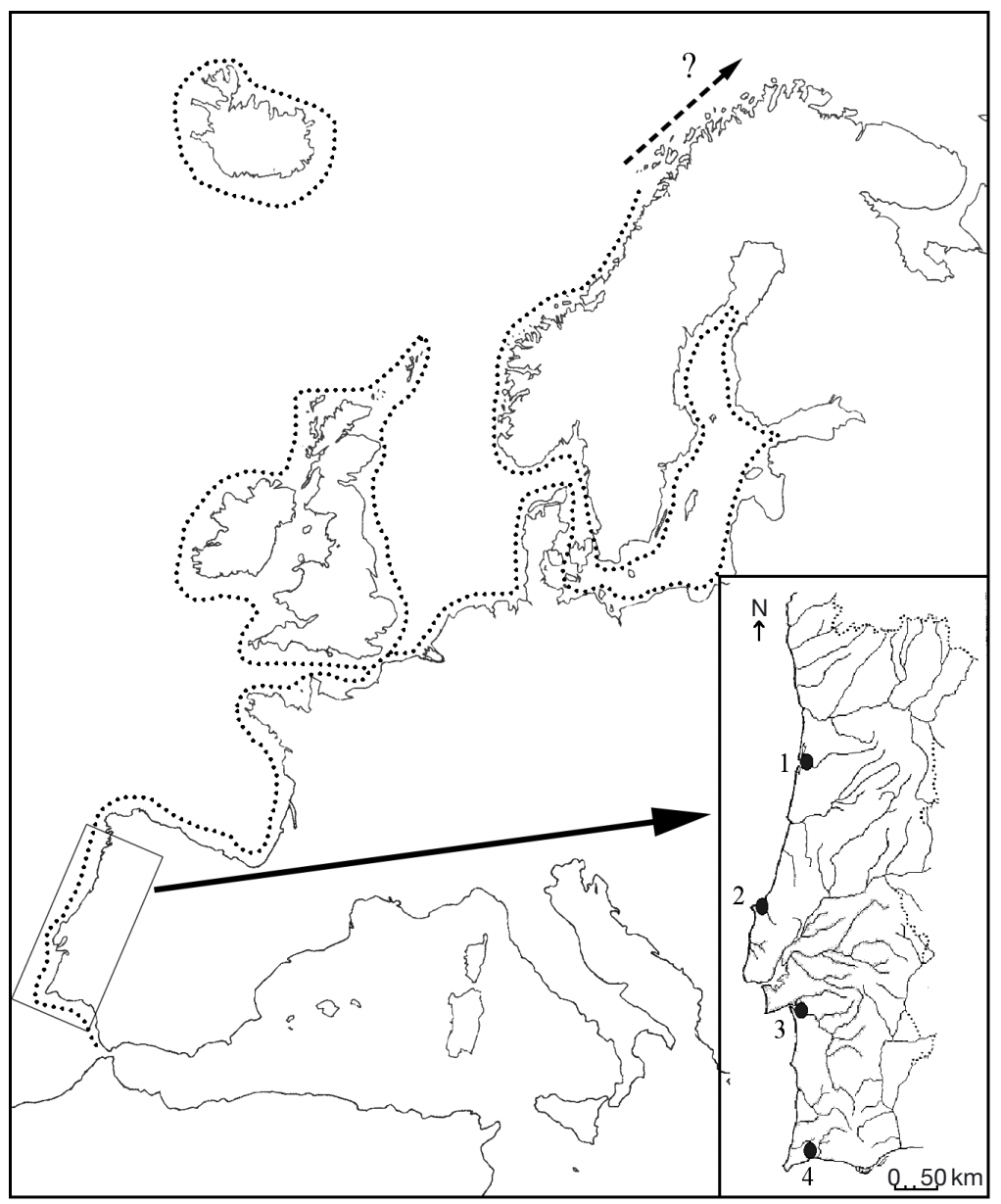

Fig. 1. Gammarus locusta. Species distribution and sampling locations of 4 populations along Portuguese coast: 1: Ria de Aveiro; 2: Foz do Arelho; 3: Sado estuary; 4: Ria de Alvor. Dotted line indicates known distribution of G. locusta. Dashed arrow: most recent information indicates that its occurrence in most northern parts of Norway is unlikely (W. Vader pers. comm. 2003)

each of dNTP, 1 U of Taq DNA polymerase, $1 \times$ PCR buffer $(20 \mathrm{mM}$ Tris- $\mathrm{HCl}$, $\mathrm{pH} 8.4,50 \mathrm{mM} \mathrm{KCl}), 3.5 \mathrm{mM} \mathrm{MgCl}_{2}$, $0.8 \mu \mathrm{M}$ of primer, and $20 \mathrm{ng}$ of template DNA. The primers used and their respective sequences were $\left(5^{\prime}-\right.$ to $\left.-3^{\prime}\right)$ : OPA2 (TGCCGAGCTG), OPA9 (GGGTAACGCC), OPA10 (GTGATCGCAG), OPA16 (AGCCAGCGAA), OPB7 (GGTGACGCAG), OPD2 (GGACCCAACC), OPD5 (TGAGCGGACA), OPD3 (GTCGCCGTCA), OPD7 (TTGGCACGGG), 4GACA (GACAGACAGACAGACA), M13 (GTAAAACGACGGCCAGT). All primers were purchased from Operon Technologies, except 4GACA and M13 (MWG Biotech). Cycling conditions consisted of initial denaturation at $95^{\circ} \mathrm{C}$ for $5 \mathrm{~min}$ followed by 40 cycles of amplification (denaturation at $93^{\circ} \mathrm{C}$ for $40 \mathrm{~s}$, annealing at $55^{\circ} \mathrm{C}$ for $60 \mathrm{~s}$, extension at $72^{\circ} \mathrm{C}$ for $60 \mathrm{~s}$, and a final extension of $6 \mathrm{~min}$ at $72^{\circ} \mathrm{C}$ ). The amplification products were maintained at $4{ }^{\circ} \mathrm{C}$ until loaded onto the gels. Electrophoresis was conducted in $2.5 \%$ agarose gels in TAE buffer (40 mM Tris, pH 7.6, 20 mM acetic acid and $1 \mathrm{mM}$ EDTA) run at $90 \mathrm{~V}$ for $2.5 \mathrm{~h}$ or for $7 \mathrm{~cm}$. The gels were stained for $30 \mathrm{~s}$ in an ethidium bromide solution $\left(30 \mathrm{mg} \mathrm{l}^{-1}\right)$, destained for $20 \mathrm{~min}$ in $\mathrm{ddH}_{2} \mathrm{O}$ and photographed under UV light. Side by side on the gel, we allocated $10 \mu \mathrm{l}$ of PCR products of the same individual, originating from 2 independent PCR reactions, to verify consistency in banding patterns. Molecular size standards consisting of $100 \mathrm{bp}$ ladders

DNA was then precipitated from the aqueous phase with ethanol, and stored at $-20^{\circ} \mathrm{C}$ for at least $2 \mathrm{~h}$ or overnight. The samples were then washed in $70 \%$ ethanol, vacuum-dried and resuspended in TEN, and the extracts subsequently digested with ribonuclease A and proteinase $\mathrm{K}$ for 1 and $2 \mathrm{~h}$, respectively, in a $55^{\circ} \mathrm{C}$ water bath, and extracted a second time with PCI and chloroform, followed by precipitation with ethanol and redissolution in TE $(10 \mathrm{mM}$ Tris and $1 \mathrm{mM}$ EDTA, $\mathrm{pH}$ 8.0). This extraction procedure is designed to minimize DNA shearing and to attain partly purified, high molecular weight DNA extracts (Theodorakis et al. 1994). DNA concentration of each sample was quantified spectrophotometrically (Unicam Helios ${ }^{\mathrm{TM}}$ ) by reading absorbancies at $260 \mathrm{~nm}$. Samples were diluted with TE to obtain final concentrations of $10 \mathrm{ng} \mathrm{ll}^{-1}$ DNA.

RAPD-PCR protocol. RAPD-PCR reactions were performed in a final volume of $12.5 \mu \mathrm{l}$, containing $0.25 \mathrm{mM}$
(Invitrogen $^{\mathrm{TM}}$ ) were run in lanes flanking groups of about 20 samples and 1 negative control in each gel.

Data treatment and statistics. After unequivocal and consistent bands were assigned to each primer, a matrix of presence (1) versus absence (0) of the selected bands was constructed. A similarity index (SI) (Lynch 1990) was used to determine within-population $\left(\mathrm{SI}_{\mathrm{W}}\right)$ and between-population $\left(\mathrm{SI}_{\mathrm{B}}\right)$ genetic similarity, as described in Theodorakis \& Shugart (1997). From $\mathrm{SI}_{\mathrm{B}}$ values, a dissimilarity (D) matrix with pairwise population dissimilarities was delineated by $\mathrm{D}=1-\mathrm{SI}_{\mathrm{B}}$.

Since RAPD markers are dominant, heterozygotes are indistinguishable from homozygotes, and allelic information is not directly available. Consequently, for analysis of allele frequency from RAPD products the following assumptions were applied: (1) RAPD products segregated as independent alleles in a Mendelian fashion, (2) genotype frequencies at RAPD loci were in 
Hardy-Weinberg proportions, (3) alleles from homozygous recessive loci were identical in state (iis) (i.e. they arose from identical mutations) among and within individuals, and (4) dominant amplified alleles were similarly iis (Apostol et al. 1996).

The levels of population differentiation were examined using 2 approaches: Wright's $F_{\mathrm{ST}}$ (Wright 1951) by means of the program RAPDFST 4.0.1 (Black 1997), and $\Phi_{\mathrm{ST}}$ as determined by analysis of molecular variance (AMOVA) using the software WINAMOVA 1.04 (Excoffier et al. 1992). In addition to Wright's $F_{\mathrm{ST}}$, Weir $\&$ Cockerman's (1984) $\theta$, and Lynch \& Milligan's (1994) $F_{\mathrm{ST}}$, were also computed, using RAPDFST along with the respective effective migration rate (number of migrants per generation) for the 3 estimates, determined as $\mathrm{Nm}=\left(1-F_{\mathrm{ST}}\right) /\left(4\left[F_{\mathrm{ST}}\right]\right)$. A value of $\mathrm{Nm}>1$ is considered sufficient for gene flow to overcome genetic drift (Wright 1931).

The data for AMOVA was prepared using the program AMOVA-PREP Version 1.01 (Miller 1998), applying the Euclidian metric of Excoffier et al. (1992) as distance coefficient. AMOVA allows partioning of variation according to different population hierarchies in order to study their influence on the inferred population structure. Based on the cluster analysis described below, a nested analysis was performed whereby 2 sources of genetic variation were considered concurrently: among regions and among populations. The regions selected were the north region, comprising Aveiro and Arelho populations, and the south region, grouping Sado and Alvor populations. AMOVA analysis was also performed considering the 2 sources of variation independently.

We determined 3 distinct genetic distance matrices using the software RAPDDIST Version 1.0 (Black \& Antolin 1997). Nei's (1978) unbiased distance (NU) and Cavalli-Sforza \& Edwards (1967) arc distance (CE) comprised genotypic approaches, and Manhattan distance (MD) (Prevosti distance in Wright 1978), a phenotypic approach. Lynch \& Milligan (1994) correction was applied to NU distance. By bootstrap analysis, 5000 matrices were produced for each of these genetic distances. Matrices were collapsed by the unweighted pair-group method of arithmetic averages (UPGMA) algorithm, using NEIGHBOR in the software package PHYLIP Version 3.6a3 (Felsenstein 2002). Consensus trees were calculated using CONSENSE from the same package. Dendrograms were constructed with the help of the program TreeView, Version 1.6.6 (Page 1996).

Maximum-likelihood estimates (MLE) of $\Theta(4 \mathrm{~N} \mu)$ and $\gamma(4 \mathrm{Nm})$ (where $\mu$ and $\mathrm{m}$ are mutation and migration rates, respectively, and $\mathrm{N}$ is the effective population size) were calculated using a full migration model (which allows for unequal population sizes and asymmetric migration rates). This model is based on coalescent theory, and obtains MLE estimates by a Markov chain Monte Carlo (MCMC) approach using the program MIGRATE 1.7.3 (Beerli \& Felsenstein 1999, 2001). Theta was used as an index of relative effective population size, assuming that mutation rates were roughly equal, or at least followed a gamma distribution (Beerli \& Felsenstein $1999,2001)$. The parameter $\gamma_{i j}$ was used as an index of the number of migrants from Population $i$ to Population $j$. The parameter $\mathrm{M}_{i j}\left(\mathrm{~m}_{i j} / \mu\right)$ (Beerli \& Felsenstein 1999, 2001) was calculated as $\gamma / \Theta$, and was used as an index of the migration rate, again assuming that mutation rates were roughly equal and/or followed a gamma distribution. Because of the dominant nature of RAPDs, a minor modification of the data for input into MIGRATE had to be implemented. MIGRATE may still be useful for dominant markers, such as RAPDs and amplified fragment length polymorphisms (AFLPs), that are scored as presence (1) or absence (0) of amplified bands, if the genotypes are coded as 0/0 for 'band absent' amplitypes and 1/? (where '?' implies an unknown allele) for 'band present' amplitypes (P. Beerli, Florida State University, pers. comm.). Using $4 \mathrm{Nm}$ data, a contingency table was constructed with the total number of migrants (emigrants + immigrants) per generation for each population. This data was then subjected to a $\chi^{2}$ test under the null hypothesis that there were no differences in the total number of migrants among populations.

\section{RESULTS}

A total of 114 scorable bands obtained from 10 primers were selected for analysis. The number of bands selected from each primer varied between 9 and 13 and, on average, $77 \%$ were polymorphic. Primer $4 \mathrm{GACA}$ showed the lowest percentage of polymorphism (56\%), while for Primer OPA16 all 13 bands were polymorphic. Results from Primer M13 were not processed further, since almost all bands were monomorphic or showed extremely low variability.

The overall average $\mathrm{SI}_{\mathrm{W}}$ value, determined combining data for all primers, was 0.841, and ranged from 0.805 in Alvor to 0.940 in Sado (Table 1). Considering each primer and population independently, the lowest $\mathrm{SI}_{\mathrm{W}}$ was recorded in Foz do Arelho for Primer OPA16 (0.682), and the highest in Sado for OPA10 (0.905). These 2 primers also had the lowest and highest average $\mathrm{SI}_{\mathrm{W}}$, respectively.

The $F_{\mathrm{ST}}$ and $\mathrm{N}_{\mathrm{m}}$ estimates were similar for all 3 methods (Table 2), with Wright's statistic presenting the higher $F_{\mathrm{ST}}$ and a reciprocally lower number of migrants per generation.

Results of the AMOVA (Table 3) identified a statistically significant but low percentage of total genetic variation that could be attributed to variation among 
Table 1. Gammarus locusta. Within-population similarity index $\left(\mathrm{SI}_{\mathrm{w}}\right)$ for each population and primer and for all primers combined, and average for each primer. Boldface indicates highest/lowest values; values in parentheses = variance

\begin{tabular}{|lcccccc|}
\hline \multirow{2}{*}{ Primer } & \multirow{2}{*}{$\begin{array}{c}\text { No. of } \\
\text { bands }\end{array}$} & Aveiro & Foz do Arelho & Sado & Alvor & Average \\
\cline { 3 - 6 } & & & & & \\
\cline { 3 - 6 } & & $0.792(0.0185)$ & $0.827(0.0147)$ & $0.870(0.0106)$ & $0.800(0.0165)$ & $0.822(0.0012)$ \\
OPA2 & 9 & $0.773(0.0157)$ & $0.823(0.0136)$ & $0.836(0.0113)$ & $0.808(0.0131)$ & $0.810(0.0007)$ \\
OPA9 & 12 & $0.878(0.0078)$ & $0.846(0.0103)$ & $\mathbf{0 . 9 0 5}(0.0061)$ & $0.888(0.0074)$ & $\mathbf{0 . 8 7 9}(0.0006)$ \\
OPA10 & 12 & $0.766(0.0149)$ & $\mathbf{0 . 6 8 2}(0.0207)$ & $0.721(0.0195)$ & $0.732(0.0182)$ & $\mathbf{0 . 7 2 6}(0.0012)$ \\
OPB7 & 13 & $0.767(0.0166)$ & $0.818(0.0126)$ & $0.757(0.0166)$ & $0.797(0.0144)$ & $0.785(0.0008)$ \\
OPD2 & 13 & $0.827(0.0172)$ & $0.868(0.0122)$ & $0.784(0.0207)$ & $0.801(0.0185)$ & $0.820(0.0013)$ \\
OPD5 & 13 & $0.839(0.0113)$ & $0.812(0.0125)$ & $0.857(0.0094)$ & $0.864(0.0092)$ & $0.843(0.0005)$ \\
OPD3 & 13 & $0.772(0.0137)$ & $0.761(0.0147)$ & $0.804(0.0120)$ & $0.733(0.0172)$ & $0.768(0.0009)$ \\
OPD7 & 11 & $0.841(0.0116)$ & $0.860(0.0097)$ & $0.829(0.0116)$ & $0.851(0.0100)$ & $0.845(0.0002)$ \\
4GACA & 9 & $0.821(0.0169)$ & $0.808(0.0193)$ & $0.798(0.0189)$ & $0.823(0.0163)$ & $0.813(0.0001)$ \\
Combined & 114 & $0.811(0.0014)$ & $0.808(0.0014)$ & $0.940(0.0002)$ & $0.805(0.0014)$ & $0.841(0.004)$ \\
\hline
\end{tabular}

populations $(4.78 \%$, nested $3.9 \%)$ or to variation among regions $(3.2 \%$, nested $1.28 \%)$. The AMOVA equivalent of $F_{\mathrm{ST}}$ (the index $\Phi_{\mathrm{ST}}$ ) was also statistically significant (but low: 0.048), when among-population variation was analyzed independently, but was not significant after nested analysis of variation among regions.

Nei's (1978) unbiased genetic distances, with Lynch \& Milligan (1994) correction, were low and averaged 0.032 (Table 4). $\mathrm{SI}_{\mathrm{B}}$ values for between-population comparisons were a little lower than for within-population comparisons, and ranged from 0.742 (Arelho-Alvor) to 0.810 (Aveiro-Sado). The respective dissimilarities are shown in the lower diagonal of Table 4.

The dendogram based on NU distances (Fig. 2) shows a distinct cluster comprising Sado and Alvor populations, which was supported by high bootstrap values (92\%) in the consensus tree derived from 5000 replicate distance matrices. The topology of this dendogram is also identical to those obtained from the CE and MD distance matrices, but is not fully in accordance with that one obtained with $\mathrm{D}$ (from $\mathrm{SI}_{\mathrm{B}}$ ).

Regarding migration data, the $\chi^{2}$ statistic obtained was $12.25\left(\chi^{2}{ }_{0.95}=7.81\right)$, thus leading to rejection of the null hypothesis. This indicates significant differences in the total number of migrants between populations. The results for the migration data are summarized in Table 5, for both the index of number of migrants per generation ( $4 \mathrm{Nm})$ and the index of per capita migration rate (M). A total of 47 migration events per generation were estimated to occur among the 4 populations. The migration ratio (number of immigrants/number of emigrants) of Alvor was considerably 
Table 4. Gammarus locusta. Distance matrix. Upper diagonal: Nei's (1978) unbiased genetic distance (NU) with Lynch \& Milligan (1994) correction; lower diagonal: dissimilarity index (D) determined from between-population similarity index $\left(\mathrm{SI}_{\mathrm{B}}\right)$

\begin{tabular}{|lcccc|}
\hline & Aveiro & F Arelho & Sado & Alvor \\
\hline Aveiro & - & 0.0399 & 0.0247 & 0.0294 \\
F Arelho & 0.217 & - & 0.0376 & 0.0413 \\
Sado & 0.190 & 0.198 & - & 0.0183 \\
Alvor & 0.245 & 0.257 & 0.235 & - \\
\hline
\end{tabular}

higher than that of the remaining populations (1.94). The Sado population had the lowest migration ratio (0.60). Between Aveiro and Arelho (both located north of Tagus estuary) dispersal is bi-directional and practically balanced. When only the 3 western coast populations are considered, north to south migration is still balanced, with the Sado estuary population contributing a number of emigrants approximately equal to the number of incoming migrants from the populations to the north. However, considering the 4 populations as a whole, migration balance is biased strongly toward the south. All populations provide substantially more emigrants to Alvor than to any other population. Emigrants from Alvor into other populations are proportionally far fewer, and their numbers decrease with increasing geographic distance. Migration flow between Alvor and Sado is fairly extensive, although the migration ratio is strongly favorable to Alvor.

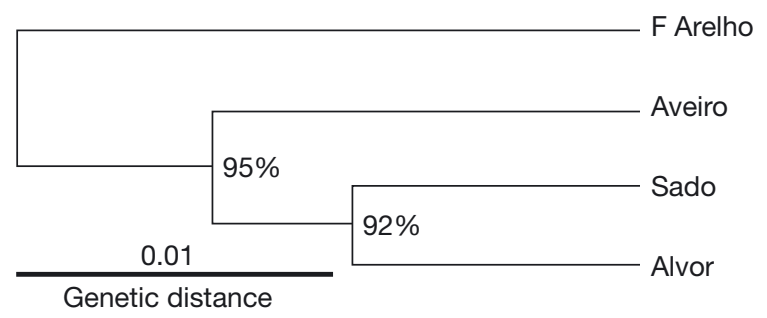

Fig. 2. Gammarus locusta. Dendogram obtained applying UPGMA clustering to Nei's (1978) unbiased genetic distance matrix. Bootstrap values of consensus tree derived from 5000 replicate matrices are shown near the respective nodes

\section{DISCUSSION}

\section{Comparison of RAPD and allozyme analyses}

Studies comparing population genetic data obtained from allozyme versus RAPD analyses have frequently found RAPD better able to detect within-population genetic variability and between-population differentiation. The higher number of loci analyzed, the higher number of mutations detectable by RAPD, and the possibility of analyzing coding and non-coding regions of the genome, are among the main reasons advanced to explain that difference (Vandewoestijne \& Baguette 2002).

Whilst the number of putative loci analyzed in the current study was much higher than the number ana-

Table 5. Gammarus locusta. Estimated patterns of migration among the 4 populations, based on Beerli \& Felsenstein's (1999, 2001) method. Table shows maximum likelihood estimators (MLE) of index of migration rate per generation (4Nm) and of index of per capita migration rate (M), with data shown as MLE (95\% confidence interval). Migration ratio and sum of $4 \mathrm{Nm}$ and $\mathrm{M}$ per population are also indicated for immigrants and emigrants; migration ratio was determined as total immigration (I) of each population total emigration (E)

\begin{tabular}{|c|c|c|c|c|c|c|}
\hline \multirow[t]{2}{*}{ From } & & & \multirow{2}{*}{\multicolumn{2}{|c|}{ Alvor }} & \multirow{2}{*}{$\begin{array}{l}\text { Total } \\
\text { emigration (E) }\end{array}$} & \multirow{2}{*}{$\begin{array}{l}\text { Migration } \\
\text { ratio (I/E) }\end{array}$} \\
\hline & Aveiro & Foz do Arelho & & & & \\
\hline \multicolumn{7}{|l|}{ Aveiro } \\
\hline $4 \mathrm{Nm}$ & - & $2.28(2.15-2.41)$ & $2.31(2.18-2.44)$ & $5.29(5.04-5.55)$ & $9.87(9.37-10.40)$ & 0.79 \\
\hline M & - & $19.5(19.0-20.0)$ & $19.8(19.3-20.3)$ & $45.3(44.5-46.1)$ & $84.6(82.8-86.3)$ & 0.92 \\
\hline \multicolumn{7}{|c|}{ Foz do Arelho } \\
\hline $4 \mathrm{Nm}$ & $2.60(2.46-2.75)$ & - & $2.27(2.13-2.40)$ & $5.91(5.64-6.19)$ & $10.78(10.23-11.35)$ & 0.80 \\
\hline M & $29.4(28.7-30.0)$ & - & $25.6(25.0-26.2)$ & $66.8(66.0-67.5)$ & $92.5(90.9-93.7)$ & 0.61 \\
\hline \multicolumn{7}{|l|}{ Sado } \\
\hline $4 \mathrm{Nm}$ & $2.39(2.25-2.54)$ & $2.59(2.45-2.74)$ & - & $10.27(9.92-10.62)$ & $15.25(14.63-15.90)$ & 0.60 \\
\hline $\mathrm{M}$ & $32.0(31.1-32.9)$ & $34.7(33.8-35.6)$ & - & $137.5(136.9-138.0)$ & $172.2(170.8-173.6)$ & 0.30 \\
\hline \multicolumn{7}{|l|}{ Alvor } \\
\hline $4 \mathrm{Nm}$ & $2.83(2.68-3.0)$ & $3.71(3.54-3.89)$ & $4.55(4.37-4.74)$ & - & 11.09 (10.58-11.09) & 1.94 \\
\hline M & $16.5(16.2-16.7)$ & $21.5(21.4-21.7)$ & $26.4(26.4-26.4)$ & - & $48.1(47.8-48.1)$ & 4.26 \\
\hline \multicolumn{7}{|c|}{ Total immigration (I) } \\
\hline $4 \mathrm{Nm}$ & $7.83(7.38-8.29)$ & $8.58(8.14-9.04)$ & $9.12(8.68-9.58)$ & $21.47(20.60-22.36)$ & & \\
\hline M & $77.9(76.0-79.7)$ & $56.2(55.2-57.3)$ & $52.1(51.4-52.6)$ & $204.3(202.9-205.5)$ & & \\
\hline \multicolumn{7}{|c|}{ Cumulative migration (I+E) } \\
\hline $4 \mathrm{Nm}$ & 17.70 & 19.36 & 24.38 & 32.56 & & \\
\hline M & 162.5 & 142.7 & 224.3 & 252.3 & & \\
\hline
\end{tabular}


lyzed in the previous allozyme study (114 versus 14), the overall results lead to the same conclusions regarding patterns of genetic variation in these populations: low differentiation between populations and low within-population genetic variability. Both betweenpopulation differentiation parameters $\left(F_{\mathrm{ST}}, \Phi_{\mathrm{ST}}, \mathrm{SI}_{\mathrm{B}}\right)$, and within-population genetic variation estimates $\left(\mathrm{SI}_{\mathrm{W}}\right)$ support this conclusion.

However, despite these results showing weak genetic differentiation among populations, it was still possible to recognize, within this slight genetic differentiation, some genetic sub-division associated with a geographic pattern. The UPGMA dendogram, derived from Nei's distances (NU), defined a clear cluster composed by Sado and Alvor populations, supported by a very high bootstrap value. Furthermore, the AMOVA analysis confirmed the existence of a statistically significant, albeit very low $(<1.5 \%)$, interpopulation genetic variation, attributable to partitioning of geographic 'regions', namely northern (Aveiro + Arelho) versus southern (Sado + Alvor) populations. Data from the migration analysis also supports this north to south pattern. The Sado population has the highest number of emigrants to Alvor and receives more emigrants from Alvor than from the other populations. The implications of this pattern will be discussed in the following subsection.

On the whole, the combined allozyme and RAPD data confirms that Gammarus locusta belongs to the 'group' of species with continuous distributions, with low within-population variability and low genetic differentiation among populations (Hogg et al. 1999). This genetic pattern has been found in other Gammarus species, for example G. fasciatus (Hogg et al. 2000), and is in contrast to that observed in amphipod species with discontinuous distributions (Hogg et al. 1999). An appreciation of the causes and implications of these patterns of low genetic variability and differentiation in G. locusta populations off the Portuguese coast is therefore required.

\section{Ecological implications of between-population differentiation}

Marine amphipod dispersal is thought to be mainly dependent on passive transport in drifting wracks, since these organisms lack larval stages. As such, surface currents are expected to influence their patterns of genetic differentiation (De Matthaeis et al. 2000a). Intrinsic features of each species, as for example salinity range or intertidal distribution, may also play a role. For instance, estuarine species of gammarids show higher genetic differentiation than marine gammarids (Bulnheim \& Scholl 1981). Genetic differentiation is also higher in 'sandhoppers' (Talitrus spp. and Talorchestia spp.) than in 'beach-fleas' (Orchestia spp. and Platorchestia spp.). While beachfleas are abundant in beach wracks close to the water line, sandhoppers occur exclusively at or above the high-water mark, and therefore the former group of amphipods is potentially more capable of dispersal (De Matthaeis et al. 2000b). Gammarus locusta has affinity with high salinities and occurs most frequently in the lower intertidal and subtidal (Costa \& Costa 2000). Therefore, considering the above examples, its dispersal potential is high compared to that of other amphipod species. Drifting attached to macroalgae is probably an important means of dispersal for this species. There is substantial evidence for the affinity of this amphipod to macroalgae, namely to loose-lying bunches of drift-macroalgae (Tully \& Ò Céidigh 1986, Costa \& Costa 2000, Vandendriessche et al. 2003).

The patterns of large-scale circulation of surface currents probably enable the extensive dispersal of drifting organisms in both directions along the Portuguese west coast. As a general rule, there are predominantly poleward and equatorward coastal flows that shift from winter to summer (upwelling season), respectively (Haynes et al. 1993, Martins et al. 2002). For instance, a RAPD study of the seaweed Gelidium sesquipedale reported low genetic differentiation between populations along the Portuguese coast (Alberto et al. 1999). This was considered to reflect the ability of surface currents to promote dispersal between populations along shore, consequently supporting broad gene flow. G. sesquipedale is considered to disperse mainly through transport and re-attachment of loose fronds, a transport strategy concurrent with the passive dispersal mode of Gammarus locusta.

Nonetheless, our migration data suggests that dispersal balance is somewhat biased in a southerly direction, i.e. from west coast populations to the southern population of Alvor. A possible explanation for this imbalance may be that the times of higher reproductive yield for Gammarus locusta coincides with those periods of the year in which the southward flow dominates. Although in Portugal this amphipod reproduces continuously throughout the year, its lowest reproductive activity and population densities occur in the winter (Costa \& Costa 1999), precisely when the northward flow dominates the surface circulation (Haynes \& Barton 1990, Martins et al. 2002).

The higher incidence of migration events among Sado and Alvor populations, on the other hand, may result in part from the oceanic circulation around Cape São Vicente, the southwesternmost tip of the Portuguese coast. During summertime the circulation is governed by the interaction of 2 regimes, an equator- 
ward flow along the west coast, and a westward countercurrent along the south coast. In periods of diminished northerly winds, this westward current bends clockwise around Cape São Vicente and continues northward for as much as $120 \mathrm{~km}$ along the west coast (Relvas \& Barton 2002). This circulation pattern is also thought to explain the low differentiation between 2 populations of Gelidium sesquipedale located on the west and south sides of the region of Cape São Vicente (Alberto et al. 1999).

Although in the current study the most southern population investigated was Alvor, the distribution of Gammarus locusta extends further east, with the species occurring in a number of locations down to Cadiz Bay (Maren 1975, Marques 1989). In Algeciras Bay, the Mediterranean location, G. locusta has not been recorded (Conradi \& López-González 1999). Hence, G. locusta can be found down to the 'door' of the Mediterranean Sea, but does not succeed in entering (and eventually colonizing) this basin. The Gibraltar Strait appears to function as a barrier to G. locusta dispersal, despite evidence of efficient dispersal mechanisms revealed in this study.

The well-documented hydrographic front in the Alborean Sea (the so-called 'Oran-Almeria Front'; Millot 1999) may have prevented the expansion of Gammarus locusta into the Mediterranean. However, 4 other Gammarus species (G. chevreuxi, G. crinicornis, G. aequicauda and G. insensibilis) occur along both the Mediterranean coast and the Portuguese west coast, and even further north (Stock 1967, Lincoln 1979, Marques 1989). Therefore the Gibraltar Strait does not appear to constitute an insurmountable geographic barrier to gammarid dispersal. Analysis of genetic differentiation patterns of populations of these Gammarus species from both basins would help clarify the impact of local hydrography in dispersal and gene flow of marine gammarids across the AtlanticMediterranean boundary. Despite the fact that several studies on fishes and invertebrates have reported restricted gene flow and the presence of a phylogeographic boundary at the Gibraltar Strait, this pattern cannot be regarded as general, as there are contradictory results among species even within the same study (Bargelloni et al. 2003).

None of the northern European marine and brackishwater Gammarus species (e.g. the so-called G. zaddachi group) occurs as far south as Gammarus locusta (Lincoln 1979). The sustainability and possible expansion of populations of G. locusta on the south Atlantic coast of Portugal and Spain, may be problematical due to the prevalence of environmental/ecological conditions that are extreme for this species. Moreover, given the absence of immigrants from the east (i.e. the Mediterranean), unless these populations, located at the edge of their distribution range, are sufficiently large to survive as a separate entity, their subsistence will be contingent upon migratory inflow from the north (i.e. an ecological 'sink'; Hogg et al. 1999).

The results of our migration analyses are consistent with the hypothesis that the Alvor population may be more 'sink-like' than the other populations, i.e. displaying a lower emigration as a result of slower growth rates and smaller population sizes. Alternatively, individuals from Alvor may be emigrating to other (unrecorded) populations (e.g. further east). A similar pattern would also be seen if there were recent periodic extinctions of Alvor followed by recolonization from other populations. In contrast, the Aveiro, Arelho and Sado populations, with low migration ratios $(<1.0)$, may be more 'source-like'; i.e. populations with positive growth rates, which provide emigrants for the sink populations (Hogg et al. 1999). Therefore, our data suggest that the western coast populations (Aveiro, Arelho and Sado) supply emigrants (and thus genetic 'information') to the southern population of Alvor, with minor feedback from Alvor.

If this is indeed the case, then the Alvor population may be more dependent on immigrants for recruitment than the other populations, and would be more at risk if there were any disturbance in the west coast-south coast dispersal flow. On the other hand, the Sado population may have an important pivotal position as the major supplier of emigrants in this population group, and consequently any disturbance in this population would have negative impacts on the other 3 populations. These results and conclusions require future validation. A priority research goal would be to determine if populations of Gammarus locusta east of Alvor also constitute a sink relative to west coast populations.

\section{Ecological implications of within-population variability}

As noted by Hogg et al. (1999), while low betweenpopulation differentiation in amphipod species with a continuous distribution can be explained by the absence of barriers to gene flow, low within-population genetic variability (compared to discontinuously distributed species) is harder to explain and requires further investigation and analysis of the potential ecological implications.

Our allozyme and RAPDs results indicate that, genetically, Gammarus locusta individuals are fairly similar regardless of their origin. Along its comparatively wide latitudinal distribution range (compared to those of other Atlantic European Gammarus species), G. locusta experiences considerable variations in its habitat, in the type of macroalgae available as food and shelter, and in competing species, predators, etc. 
These environmental variations become even broader if we include the particular environmental conditions of the Baltic Sea. How does the genetic shaping and genotypic diversity of $G$. locusta populations correspond with these characteristics? While its geographic distribution indicates that apparently this species has a wide ecological range, it has also been found to be among the most sensitive Gammarus species to a range of stresses, including oxygen depletion, acclimation period, chemical toxicity and anthropogenic disturbance in general (Costa \& Costa 2000, Gaston \& Spicer 2001).

One possible explanation for this inconsistency lies in the demographic and reproductive features of this amphipod. Field, laboratory, and mesocosms studies have shown that Gammarus locusta has a high potential to develop huge population densities in a relatively short period of time, thanks to its comparatively high fecundity, fast growth rates and short life-cycle (Costa \& Costa 1999, Neuparth et al. 2002, Christie \& Kraufvelin 2003). Thus, this species can take advantage of favorable ecological conditions to colonize new habitats and develop large populations in a short period. Conversely, due to its sensitivity to environmental disturbance, large populations may vanish very quickly (Costa \& Costa 1999).

Future genetic studies should cover the whole geographic distribution range of Gammarus locusta. Application of other molecular techniques with different scope and resolution may also add new and relevant information to the topics discussed here. At this stage, particular focus is required on populations along the Iberian south Atlantic coast, and laboratory and field observations should specifically examine the role of genetic variability in coping with environmental threats. The case study of the Baltic Sea should also be subjected to investigation, since the unique situation there challenges many of the inferences made above. According to Kolding (1985), Baltic Sea populations of G. locusta are reproductively isolated from nearby populations by their different salinity tolerance limits; i.e., there is no common salinity at which both Baltic and non-Baltic populations can survive or reproduce. Yet, Kolding (1985) did not find any genetic differentiation between these physiologically isolated groups. In this case, low genetic differentiation can not be explained by extended gene flow and dispersal between the 2 population groups. This imposes some reserves on the assumption that low genetic differentiation among populations of $G$. locusta is a consequence of extended gene flow. Therefore, genetic investigation of Baltic Sea populations may contribute to our knowledge of the ecology of G. locusta and of genome-environment relationships in Gammarus species.
Acknowledgements. We are grateful to Dr. W. Vader (University of Tromsø, Norway) for information regarding the distribution of Gammarus locusta along the Norwegian coast. We would also like to thank the anonymous referees for their comments and to acknowledge their contribution in improving the manuscript. This work was supported by research grant PRAXIS/P/BIA/10225/98 and fellowships BD/11575/97 and BD/21613/99 from 'Fundação para a Ciência e Tecnologia'.

\section{LITERATURE CITED}

Alberto F, Santos R, Leitão JM (1999) Assessing patterns of geographic dispersal of Gelidium sesquipedale (Rhodophyta) through RAPD differentiation of populations. Mar Ecol Prog Ser 191:101-108

Apostol BL, Black WC, IV, Reiter P, Miller BR (1996) Population genetics with RAPD-PCR markers: the breeding structure of Aedes aegypti in Puerto Rico. Heredity 76:325-334

Bargelloni L, Alarcon JA, Alvarez MC, Penzo E, Magoulas A, Reis C, Patarnello T (2003) Discord in the family Sparidae (Teleostei): divergent phylogeographical patterns across the Atlantic-Mediterranean divide. J Evol Biol 16: $1149-1158$

Beerli P, Felsenstein J (1999) Maximum likelihood estimation of migration rates and effective population numbers in two populations using a coalescent approach. Genetics 152: 763-773

Beerli P, Felsenstein J (2001) Maximum likelihood estimation of a migration matrix and effective population sizes in $n$ subpopulations by using a coalescent approach. Proc Natl Acad Sci USA 98:4563-4568

Bickham JW, Sandhu S, Hebert PDN, Chikki L, Athwal R (2000) Effect of chemical contaminants on genetic diversity in natural populations: implications for biomonitoring and ecotoxicology. Mutat Res 463:33-51

Black WC, IV (1997) RAPDFST-A FORTRAN program to estimate $\mathrm{F}(\mathrm{ST})$ and effective migration rates among subpopulations using RAPD-PCR files. Colorado State University, Fort Collins

Black WC, IV, Antolin M (1997) FORTRAN programs for the analysis of RAPD-PCR markers: RAPDDIST. Colorado State University, Fort Collins

Bulnheim HP, Scholl A (1981) Genetic variation between geographic populations of the amphipods Gammarus zaddachi and G. salinus. Mar Biol 64:105-115

Cavalli-Sforza LL, Edwards AWF (1967) Phylogenetic analysis: models and estimation procedures. Evolution 21: $550-570$

Christie H, Kraufvelin P (2003) Mechanisms regulating amphipod population density within macroalgal communities with low predator impact. Sci Mar 68:189-198

Coelho H, Costa FO, Costa MH, Coelho MM (2002) Low genetic variability of the widespread amphipod Gammarus locusta, as evidenced by allozyme electrophoresis of southern European populations. Crustaceana 75:1335-1348

Congiu L, Rossi R, Colombo G (2002) Population analysis of the sand smelt Atherina boyeri (Teleostei, Atherinidae), from Italian coastal lagoons by random amplified polymorphic DNA. Mar Ecol Prog Ser 229:279-289

Conradi M, López-González PJ (1999) The benthic Gammaridea (Crustacea, Amphipoda) fauna of Algeciras Bay (Strait of Gibraltar): distributional ecology and some biogeographical considerations. Helgol Meeresunters Res 53: $2-8$ 
Costa FO, Costa MH (1999) Life history of the amphipod Gammarus locusta in the Sado estuary (Portugal). Acta Oecol 20:305-314

Costa FO, Costa MH (2000) Review of the ecology of Gammarus locusta (L.). Pol Arch Hydrobiol 48:541-559

Costa FO, Correia AD, Costa MH (1998) Acute marine sediment toxicity: a potential new test with the amphipod Gammarus locusta. Ecotoxicol Environ Saf 40:81-87

De Matthaeis E, Davolos D, Cobolli M, Ketmaier V (2000a) Isolation by distance in equilibrium and nonequilibrium populations of four talitrid species in the Mediterranean Sea. Evolution 54:1606-1613

De Matthaeis E, Ketmaier V, Davolos D, Schembri PJ (2000b) Patterns of genetic diversity in Mediterranean supralittoral amphipods (Crustacea, Amphipoda). Pol Arch Hydrobiol 47:473-487

Exadactylos A, Geffen AJ, Panagiotaki P, Thorpe JP (2003) Population structure of Dover sole Solea solea: RAPD and allozyme data indicate divergence in European stocks. Mar Ecol Prog Ser 246:253-264

Excoffier L, Smouse PE, Quattro JM (1992) Analysis of molecular variance inferred from metric distances among DNA haplotypes: application to human mitochondrial DNA restriction data. Genetics 131:479-491

Felsenstein J (2002) PHYLIP (phylogeny inference package) Version 3.6a3. Department of Genome Sciences, University of Washington, Seattle (distributed by the author)

Gaston KJ, Spicer JI (2001) The relationship between range size and niche breadth: a test using five species of Gammarus (Amphipoda). Glob Ecol Biogeogr Lett 10:179-188

Haynes R, Barton D (1990) A poleward flow along the Atlantic coast of the Iberian Peninsula. J Geophys Res 95: $11425-11442$

Haynes R, Barton D, Pilling I (1993) Development, persistence, and variability of upwelling filaments off the Atlantic coast of the Iberian Peninsula. J Geophys Res 12:22681-22692

Heipel DA, Bishop JDD, Brand AR, Thorpe JP (1998) Population genetic differentiation of the great scallop Pecten maximus in western Britain investigated by randomly amplified polymorphic DNA. Mar Ecol Prog Ser 162:163-171

Hilbish TJ (1996) Population genetics of marine species: the interaction of natural selection and historically differentiated populations. J Exp Mar Biol Ecol 200:67-83

Hogg ID, Eadie JM, Lafontaine Y (1999) Passive dispersal among fragmented habitats: the population genetic consequences for freshwater and estuarine amphipods. In: Schram ER, von Vaupel Klein JC (eds) Crustaceans and the biodiversity crisis, Vol 1. Brill, Leiden, p 307-326

Hogg ID, Lafontaine Y, Eadie JM (2000) Genotypic variation among Gammarus fasciatus (Crustacea: Amphipoda) from the Great Lakes-St. Lawrence River. Can J Fish Aquat Sci 57:1843-1852

Kolding S (1985) Genetic adaptation to local habitats and speciation processes within the genus Gammmarus (Amphipoda: Crustacea). Mar Biol 89:249-255

Krane DE, Sternberg DC, Burton GA (1999) Randomly amplified polymorphic DNA profile-based measures of genetic diversity in crayfish correlated with environmental impacts. Environ Toxicol Chem 18:504-508

Lincoln RJ (1979) British marine Amphipoda: Gammaridea. British Museum (Natural History), London

Lynch M (1990) The similarity index and RAPD DNA fingerprinting. Mol Biol Evol 7:478-489

Lynch M, Milligan BG (1994) Analysis of population genetic structure with RAPD markers. Mol Ecol 3:91-99

Mamuris Z, Stamatis C, Bani M, Triantaphyllidis C (1999)
Taxonomic relationships between four species of the Mullidae family revealed by three genetic methods: allozymes, random amplified polymorphic DNA and mitochondrial DNA. J Fish Biol 55:572-587

Maren MJV (1975) Some notes on the intertidal gammarids (Crustacea, Amphipoda) from the Atlantic coast of the Iberian Peninsula. Beaufortia 23:153-168

Marques JC (1989) Amphipoda (Crustacea) bentónicos da costa portuguesa: estudo taxonómico, ecológico e biogeográfico. $\mathrm{PhD}$ thesis, Universidade de Coimbra

Martins CS, Hamann M, Fiuza AFG (2002) Surface circulation in the eastern North Atlantic, from drifters and altimetry. J Geophys Res 107:3217

McCormack GP, Powell R, Keegan BF (2000) Comparative analysis of two populations of the brittle star Amphiura filiformis (Echinodermata: Ophiuroidea) with different life history strategies using RAPD markers. Mar Biotechnol 2:100-106

Miller MP (1998) AMOVA-PREP. Northern Arizona University, Flagstaff

Millot C (1999) Circulation in the Western Mediterranean Sea. J Mar Syst 20:423-442

Nei M (1978) Estimation of average heterozygosity and genetic distance from a small number of individuals. Genetics 89:583-590

Neuparth T, Costa FO, Costa MH (2002) Effects of temperature and salinity on life history of the marine amphipod Gammarus locusta. Implications for ecotoxicological testing. Ecotoxicology 11:61-73

Page RDM (1996) TreeView: an application to display phylogenetic trees on personal computers. Comput Appl Biosci 12:357-358

Relvas P, Barton ED (2002) Mesoscale patterns in the Cape São Vicente (Iberian Peninsula) upwelling region. J Geophys Res 107:3164

Siegismund HR, Simonsen V, Kolding S (1985) Genetic studies of Gammarus. I. Genetic differentiation of local populations. Hereditas 102:1-13

Silbiger RN, Leonard AC, Dimsoski $\mathrm{P}$, Foré $\mathrm{S}$ and 6 others (2001) Use of molecular markers to study the effects of environmental impacts on genetic diversity in brown bullhead (Ameirus nebulosus) populations. Environ Toxicol Chem 20:2580-2587

Star B, Apte S, Gardner JPA (2003) Genetic structuring among populations of the greenshell mussel Perna canaliculus revealed by analysis of randomly amplified polymorphic DNA. Mar Ecol Prog Ser 249:171-182

Stock JH (1967) A revision of the European species of the Gammarus locusta-group (Crustacea, Amphipoda). Zool Verh 90:1-56

Theodorakis CW, Shugart LR (1997) Genetic ecotoxicology. II: population genetic structure in mosquitofish exposed in situ to radionuclides. Ecotoxicology 6:335-354

Theodorakis CW, Shugart LR (1999) Natural selection in contaminated environments: a case study using RAPD genotypes. In: Forbes V (ed) Genetics and ecotoxicology. Taylor \& Francis, Washington, DC, p 123-149

Theodorakis CW, D'Surney SJ, Shugart LR (1994) Detection of genotoxic insult as DNA strand breaks in fish blood cells by agarose gel electrophoresis. Environ Toxicol Chem 13:1023-1031

Theodorakis CW, Bickham JW, Lamb T, Medica PA, Lyne TB (2001) Integration of genotoxicity and population genetic analyses in Kangaroo rats (Dipodomys merriami) exposed to radionuclide contamination at the Nevada test site, USA. Environ Toxicol Chem 20:317-326

Thomas PE, Blinn DW, Keim P (1997) Genetic and behavioural 
divergence among desert spring amphipod populations. Freshw Biol 38:137-143

Tully O, Ò Céidigh P (1986) The ecology of Idotea species (Isopoda) and Gammarus locusta (Amphipoda) on surface driftweed in Galway Bay (West of Ireland). J Mar Biol Assoc UK 66:931-942

Ulrich I, Müller J, Schütt C, Buchholz F (2001) A study of population genetics in the European lobster Homarus gammarus (Decapoda, Nephropidae). Crustaceana 74: 825-837

Vandendriessche S, Degraer S, Vincx M (2003) Drijvende wieren als habitat voor macrofauna aan de Belgische kust. Strandvlo 23:50-58

Vandewoestijne S, Baguette M (2002) The genetic structure of endangered populations in the cranberry fritillary,

Editorial responsibility: Otto Kinne (Editor),

Oldendorf/Luhe, Germany
Boloria aquilonaris (Lepidoptera, Nymphalidae): RAPDs vs allozymes. Heredity 89:439-445

Weir BS, Cockerham CC (1984) Estimating F-statistics for the analysis of population structure. Evolution 38:1358-1370

Wilson AB, Boates JS, Snyder M (1997) Genetic isolation of populations of the gammaridean amphipod, Corophium volutator, in the Bay of Fundy, Canada. Mol Ecol 6: 917-923

Wright S (1931) Evolution in Mendelian populations. Genetics 16:97-157

Wright S (1951) The genetical structure of populations. Ann Eugen 15:323-354

Wright S (1978) Evolution and the genetics of populations, Vol. 4, Variability within and among natural populations. University of Chicago Press, Chicago

Submitted: May 26, 2003; Accepted: April 20, 2004

Proofs received from author(s): August 6, 2004 